EPJ Web of Conferences 106, 01003 (2016)

DOI: $10.1051 /$ epjconf/201610601003

(C) Owned by the authors, published by EDP Sciences, 2016

\title{
Neutron Environment Characterization of the Central Cavity in the Annular Core Research Reactor ${ }^{\mathrm{a}}$
}

\author{
Edward J. Parma ${ }^{1, \mathrm{~b}}$, Gerald E. Naranjo ${ }^{2}$, Lance L. Lippert ${ }^{3}$, and David W. Vehar ${ }^{1}$
}

${ }^{1}$ Principal R\&D Scientist/Engineer, Applied Nuclear Technologies, Sandia National Laboratories, Albuquerque, New Mexico, USA

${ }^{2}$ Distinguished Technologist, Advanced Nuclear Concepts, Sandia National Laboratories, Albuquerque, New Mexico, USA

${ }^{3}$ Nuclear Reactor Engineer and Operator, Nuclear Facility Operations, Sandia National Laboratories, Albuquerque, New Mexico, USA

\begin{abstract}
Characterization of the neutron environment in the central cavity of the Sandia National Laboratories' Annular Core Research Reactor (ACRR) is important in order to provide experimenters with the most accurate spectral information and maintain a high degree of fidelity in performing reactor experiments. Characterization includes both modeling and experimental efforts. Building accurate neutronic models of the ACRR and the central cavity "bucket" environments that can be used by experimenters is important in planning and designing experiments, as well as assessing the experimental results and quantifying uncertainties. Neutron fluence characterizations of two bucket environments, LB44 and PLG, are presented. These two environments are used frequently and represent two extremes in the neutron spectrum. The LB44 bucket is designed to remove the thermal component of the neutron spectrum and significantly attenuate the gamma-ray fluence. The PLG bucket is designed to enhance the thermal component of the neutron spectrum and attenuate the gamma-ray fluence. The neutron characterization for each bucket was performed by irradiating 20 different activation foil types, some of which were cadmium covered, resulting in 37 different reactions at the peak axial flux location in each bucket. The dosimetry results were used in the LSL-M2 spectrum adjustment code with a 640-energy group MCNP-generated trial spectrum, self-shielding correction factors, the SNLRML or IRDFF dosimetry cross-section library, trial spectrum uncertainty, and trial covariance matrix, to generate a least-squares adjusted neutron spectrum, spectrum uncertainty, and covariance matrix. Both environment character-izations are well documented and the environments are available for use by experimenters.
\end{abstract}

\footnotetext{
${ }^{a}$ Work supported by the United States Department of Energy at Sandia National Laboratories. Sandia National Laboratories is a multi-program laboratory managed and operated by Sandia Corporation, a wholly owned subsidiary of Lockheed Martin Corporation, for the U.S. Department of Energy's National Nuclear Security Administration under contract DE-AC0494AL85000.

${ }^{\mathrm{b}}$ Corresponding author: ejparma@sandia.gov
}

This is an Open Access article distributed under the terms of the Creative Commons Attribution License 2.0, which permits unrestricted use, distribution, and reproduction in any medium, provided the original work is properly cited. 


\section{Introduction}

The Annular Core Research Reactor (ACRR) is a pulse and steady-state pool-type research reactor that maintains a large, dry irradiation cavity at the center of its core. The ACRR is typically used to perform irradiation testing where a high neutron flux is required for a short period of time. Historically, the ACRR has been used for a wide variety of experiment campaigns including weapons effects testing, nuclear fuels testing, nuclear pumped laser experiments, space nuclear thermal propulsion testing, and medical isotopes production. The ACRR's main attributes include a large, dry central irradiation cavity, epithermal neutron fluence, and large pulsing capabilities. The ACRR is located in Technical Area V (TA-V) at Sandia National Laboratories in Albuquerque, New Mexico. The reactor, in its current configuration, was assembled in 1978 to accommodate large experiments at the center of its core and to have large pulsing capabilities. The fuel elements for the ACRR are similar in size and shape to TRIGA fuel. However, the fuel is unique in that it is uranium dioxide/beryllium oxide (UO2-BeO) that was specially designed to have a large heat capacity and, thus, larger pulsing capabilities. The maximum ACRR pulse energy is 300 MJ. Figure 1 shows a picture of the ACRR looking into the pool from floor level. The ACRR is shown on the right in the figure. The 9-inch $(22.9 \mathrm{~cm})$ diameter dry cavity extends from above the pool through the center of the core. The reactor facility also accommodates the fueled ring external cavity (FREC), shown on the left in the figure, which maintains a larger dry cavity [20-inch $(50.8 \mathrm{~cm})$ diameter] and uses U-ZrH TRIGA fuel as a subcritical multiplier. FREC provides the user with a larger experimental volume and the fuel arrangement limits the neutron flux gradient across the test volume.

The ACRR maintains an epithermal neutron fluence spectrum in the core and central cavity. This allows the neutron energy fluence spectrum to be tailored to the desired specifications of an experiment. Moderators can be used within the cavity to thermalize the neutron spectrum. Boron and lead can be used to increase the fast neutron fluence ratio and to decrease the gamma-ray fluence, respectively. For an unmoderated free-field condition, the neutron fluence at the center of the central cavity, at the core axial centerline, is $\sim 2.0 \mathrm{E} 13 \mathrm{n} / \mathrm{cm}^{2}$ per MJ of reactor energy. About $45 \%$ of the neutron fluence is above $100 \mathrm{keV}$ and $\sim 56 \%$ is above $10 \mathrm{keV}$. The $1-\mathrm{MeV}$ damage-equivalent silicon fluence is $\sim 7.9 \mathrm{E} 12 \mathrm{n} / \mathrm{cm}^{2}$ per MJ. The prompt gamma-ray dose at the same position is $\sim 77 \mathrm{~Gy}(\mathrm{Si})$ per MJ. The delayed gamma-ray dose is $\sim 33 \mathrm{~Gy}(\mathrm{Si})$ per $\mathrm{MJ}$.

Several neutron and gamma-ray spectrum-modifying buckets have been built and used in the central cavity over the years, and others are being considered for future construction. The LB44 bucket has lead and $\mathrm{B}_{4} \mathrm{C}$ powder annuli in the outermost radial regions; it is designed to remove the thermal component of the neutron spectrum and significantly attenuate the gamma-ray fluence. Other bucket configurations are used to enhance the thermal component of the neutron spectrum using polyethylene, or to produce more gamma-rays using a combination of polyethylene and cadmium. The PLG bucket has lead, polyethylene, and graphite powder annuli to enhance the thermal component of the neutron spectrum and attenuate the gamma-ray fluence.

\section{Neutronics Modeling}

The Monte Carlo N-Particle transport code, MCNP5 version 1.60 [1], was used to model the ACRR and the bucket environments. Figures 2 and 3 show the MCNP model of the ACRR [2] with the LB44 bucket and the PLG bucket, respectively, on the 32 -inch $(81.3 \mathrm{~cm})$ pedestal in the central cavity. The FREC-II model was not included because it is neutronically decoupled (tilted back) from the ACRR for these operations. A 6-cm diameter tally sphere is modeled at the axial centerline of the cavity. The neutron energy spectrum was calculated for a 640-energy group and an 89-energy group structure using the ENDF/B-VII cross sections at $300 \mathrm{~K}$. The models were run in the KCODE mode using both neutrons and photons. This allowed for both the neutron energy spectrum and the prompt gamma-ray 


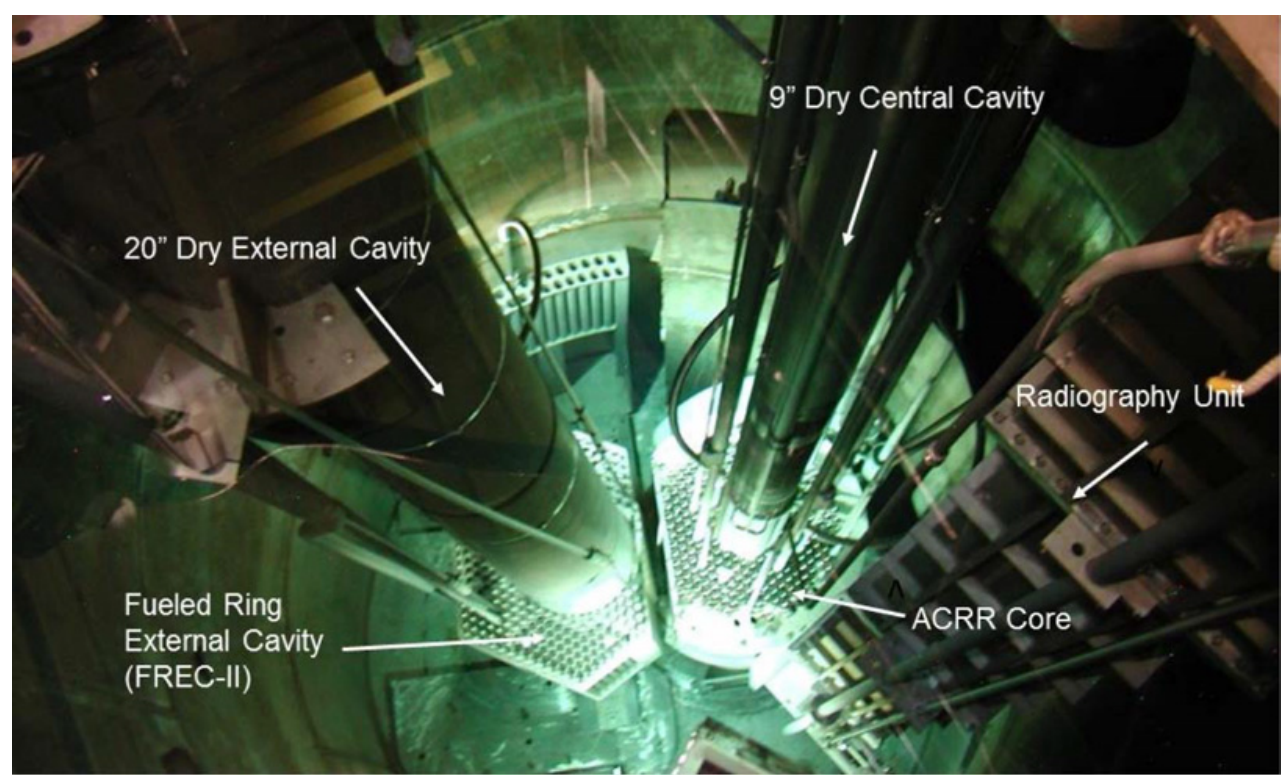

Figure 1. The ACRR with FREC-II in the decoupled configuration. The Radiography Unit is shown on the right.

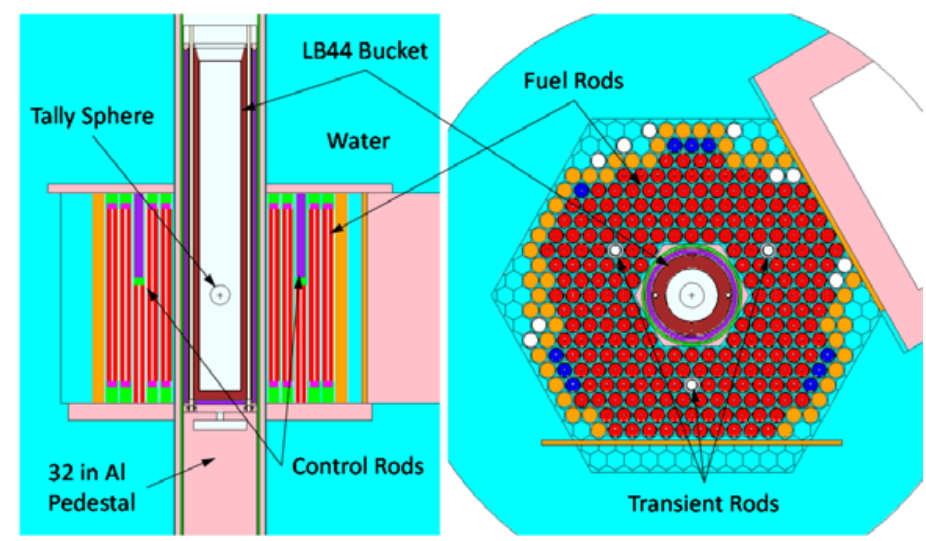

Figure 2. MCNP model of the ACRR with the LB44 bucket on the 32 -inch $(81.3 \mathrm{~cm})$ pedestal.

energy spectrum to be calculated in a single run. The gamma-ray spectrum was also calculated using a 48-energy group structure. In order to have reasonable statistics in all of the energy groups, the model was run on a parallel machine for 20 billion source neutrons. The 640-energy group neutron spectrum result was used as the trial function for the LSL-M2 code [3].

\section{Neutron Activation Dosimetry}

The initial characterization of each bucket included a neutron and gamma-ray axial and radial profile mapping to determine the peak and variation. Sulfur tablets and $\mathrm{CaF}_{2}: \mathrm{Mn}$ TLDs were used to perform the axial mapping in 1-cm increments from the bottom of each bucket up to $90 \mathrm{~cm}$. The peak neutron flux was found to be at $\sim 11$ inches $(27.9 \mathrm{~cm})$ from the bottom of both buckets. The flux was relatively 


\section{EPJ Web of Conferences}

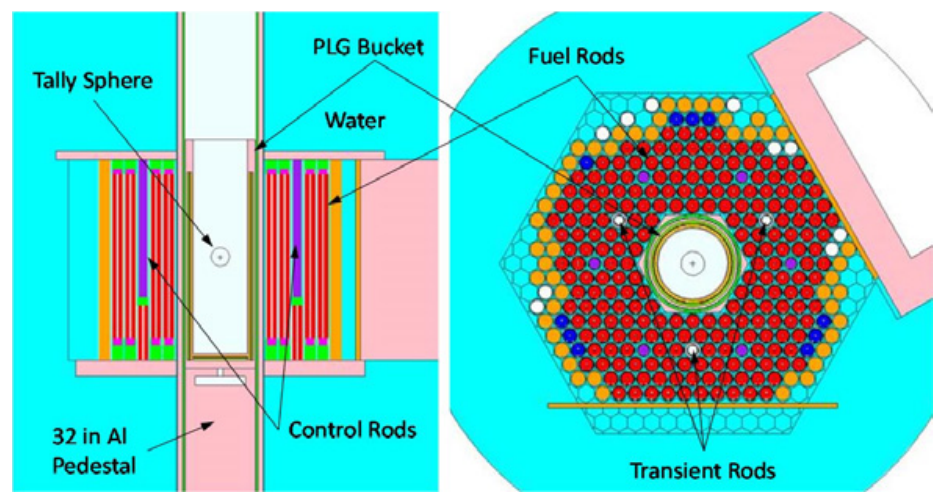

Figure 3. MCNP model of the ACRR with the PLG bucket on the 32 -inch $(81.3 \mathrm{~cm})$ pedestal.
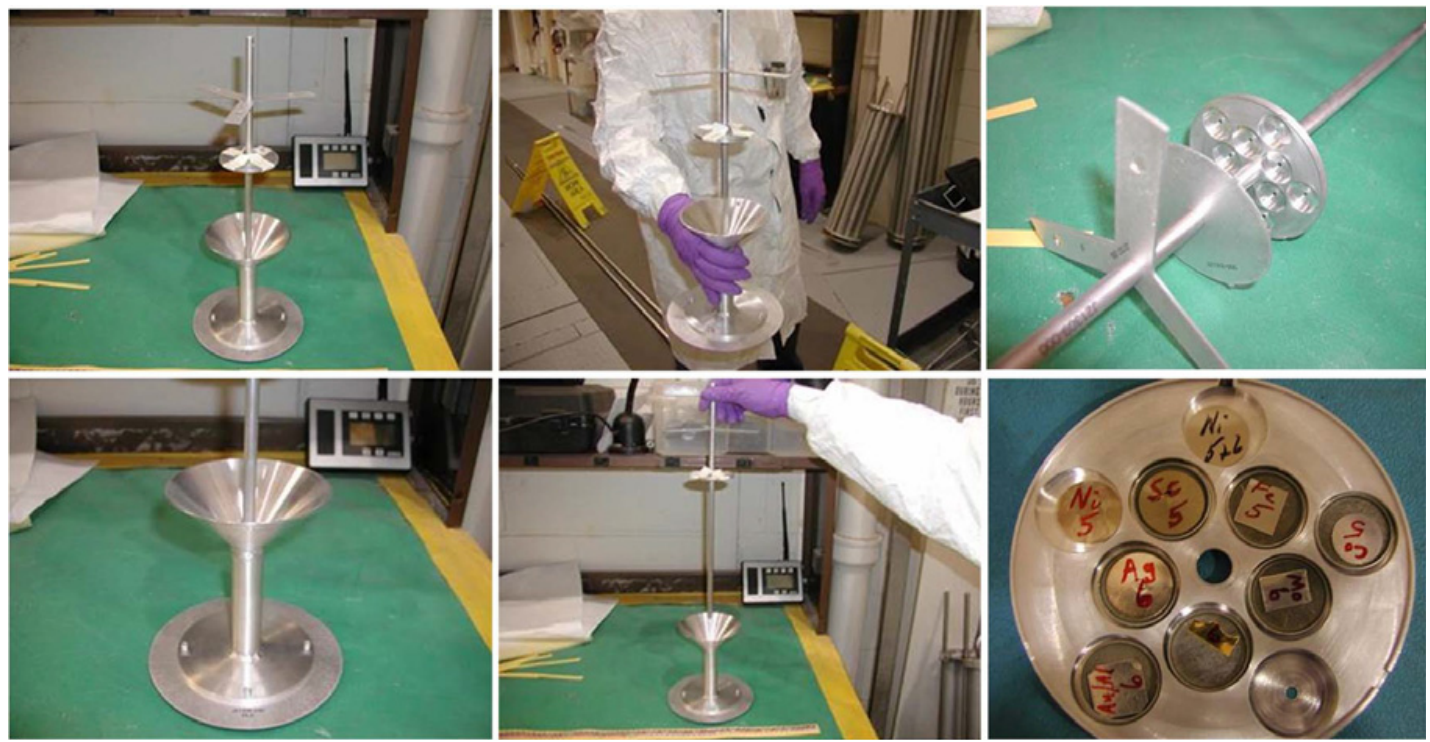

Figure 4. Dosimetry stand used to perform activation foil irradiations at the peak neutron flux.

constant (within a few percent) over $\sim 4$ inches $(10 \mathrm{~cm})$. Radial mapping was performed using sulfur tablets, gold foils and $\mathrm{CaF}_{2}: \mathrm{Mn}$ TLDs. No significant radial variation was observed for either bucket.

Neutron activation foils were irradiated at the peak fluence location using an aluminum dosimetry stand (see Fig. 4) that was designed to facilitate the irradiations and to minimize personnel dose. The stand is made up of two parts: the funnel, which stays in the bucket, and the drop-in thimble, which holds up to 10 foils at one time. The mass of the thimble is minimal to reduce personnel dose. The thimble is lowered and raised from the top of the cavity into the funnel using a simple nylon cord. The funnel centers and secures the thimble within the bucket at the peak neutron fluence location.

Dosimetry-quality foils were used to perform the neutron activation. The selection of foils was made using expert judgement with reference to past work [4, 5]. Several operations were required to irradiate all of the desired foils. For each operation, a nickel (Ni) foil was also irradiated to allow for all of the operations to be normalized to a given operating condition. For LB44, 18 different activation foil types were used, some of which were cadmium $(\mathrm{Cd})$ covered, resulting in 31 different reactions. Four 

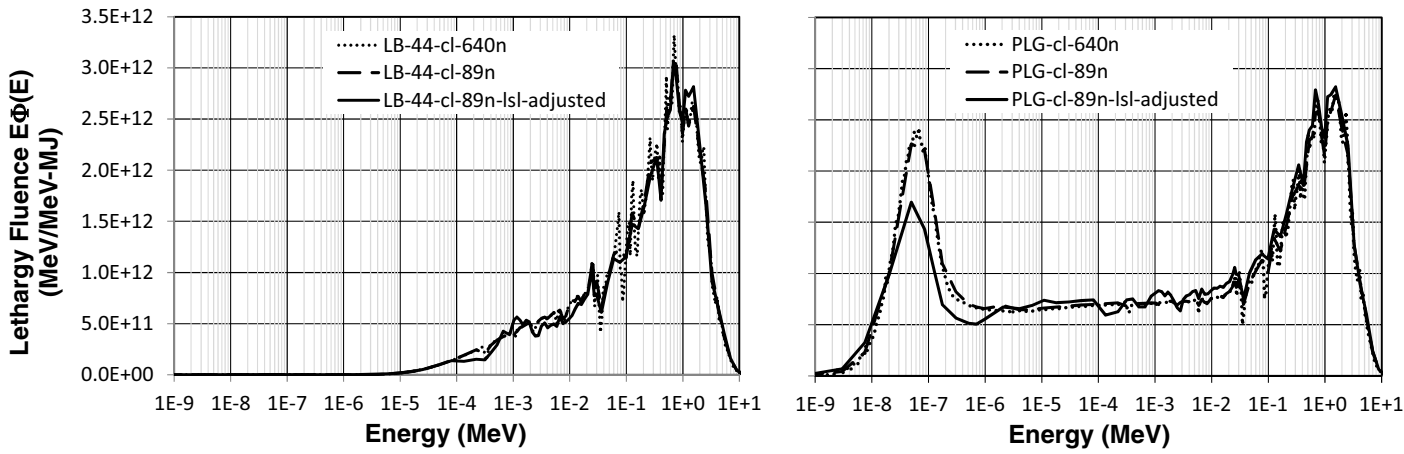

Figure 5. Neutron Lethargy Fluence for the LB44 bucket (left) and the PLG bucket (right). Shown are the 640 group trial spectrum, the 89 group trial spectrum, and the 89 group LSL adjusted spectrum.

fission foils $\left({ }^{235} \mathrm{U},{ }^{238} \mathrm{U},{ }^{239} \mathrm{Pu}\right.$, and $\left.{ }^{237} \mathrm{~Np}\right)$ were irradiated individually in a standard $\mathrm{Cd}$ and boron ball configuration in four separate steady-state operations. The activation foils were irradiated at a maximum pulse operation for the LB44 bucket of 300 MJ. A total of 10 operations were required to irradiate all of the foils. For PLG, 20 different foil types were used, some of which were Cd covered, resulting in 37 different reactions. Fission foils were also irradiated individually using boron balls. The activation foils were irradiated at a maximum pulse operation for the PLG bucket of 150 MJ. A total of 10 operations were required to irradiate all of the foils. After each operation, the dosimetry stand thimble was removed from the ACRR cavity after a cool down period of $\sim 1$ hour. Depending on the half-life of the foils, the thimble was allowed to decay in a shielded area for hours to days. The foils were then removed from the thimble and packaged with appropriate information for counting at the Sandia Radiation Metrology Laboratory (RML) located adjacent to the ACRR facility. Foil activity data from the RML were collected and assembled into a spreadsheet for further analysis.

\section{Neutron Spectrum Adjustment/Unfold Results}

The dosimetry activation foil results were used in the LSL-M2 spectrum adjustment code [3] with the 640-energy group MCNP-generated trial spectrum, self-shielding correction factors [6], the SNLRML [7] or IRDFF [8, 9] dosimetry cross-section library, trial spectrum uncertainty, and trial covariance matrix, to generate a least-squares adjusted neutron spectrum, uncertainty, and covariance matrix. The LSL-M2 adjustment process generated an 89-energy group spectrum. Table 1 shows the results of the LSL analysis for the LB44 bucket. The resulting $\chi^{2}$ per degree of freedom for the adjustment was 0.89, an acceptable value. Table 2 shows the results for the PLG bucket. The resulting $\chi^{2}$ per degree of freedom for the adjustment was 0.80, an acceptable value. For both cases, the adjusted spectrum was modified only by a few percent in the fast neutron region represented by the (n,p), (n,2n), $(\mathrm{n}, \alpha)$, and (n,n') reactions. The adjustment was much more significant in the thermal and epithermal regions represented by the $(\mathrm{n}, \gamma)$ and Cd covered $(\mathrm{n}, \gamma)$ reactions.

Figures 5 through 7 show the trial and adjusted neutron fluence spectrum, the percent adjustment and uncertainty, and the reaction probability, respectively, as a function of energy for the LB44 bucket (left in each figure) and the PLG bucket (right) for the LSL analysis. The y-axis for Figure 5 is in units of lethargy fluence or energy fluence, equal to $\mathrm{E} \mathrm{d} \phi / \mathrm{dE}$ ( $\left.\mathrm{MeV} / \mathrm{MeV}-\mathrm{cm}^{2}-\mathrm{MJ}\right)$. With the energy flux represented linearly on the $y$-axis and the neutron energy on the $\mathrm{x}$-axis represented logarithmically, the area under the curve represents the total neutron flux. This representation allows for the best visual depiction of the flux over the complete neutron energy range. The flux value for each energy group is represented at the average energy for the group. 
Table 1. C/E values for the trial and adjusted LSL neutron energy spectrum for the LB44 bucket.

\begin{tabular}{|c|c|c|c|}
\hline Activation Reaction & $\begin{array}{c}\text { C/E-1 } \\
\text { Trial Spectrum (\%) }\end{array}$ & $\begin{array}{c}\text { C/E-1 } \\
\text { Adjusted Spectrum (\%) }\end{array}$ & Factor Adjusted (\%) \\
\hline${ }^{58} \mathrm{Ni}(\mathrm{n}, \mathrm{p}){ }^{58} \mathrm{Co}-$ Reference & 0.00 & -0.82 & -0.83 \\
\hline${ }^{59} \mathrm{Co}(\mathrm{n}, \mathrm{p}){ }^{59} \mathrm{Fe}$ & 2.86 & 1.54 & -1.30 \\
\hline${ }^{27} \mathrm{Al}(\mathrm{n}, \alpha)^{24} \mathrm{Na}$ & 8.35 & 5.71 & -2.50 \\
\hline${ }^{27} \mathrm{Al}(\mathrm{n}, \mathrm{p}){ }^{27} \mathrm{Mg}$ & -8.73 & -1.64 & 7.21 \\
\hline${ }^{46} \mathrm{Ti}(\mathrm{n}, \mathrm{p})^{46} \mathrm{Sc}$ & -3.49 & -0.81 & 2.70 \\
\hline${ }^{47} \mathrm{Ti}(\mathrm{n}, \mathrm{p})^{47} \mathrm{Sc}$ & 3.35 & 0.81 & -2.52 \\
\hline${ }^{48} \mathrm{Ti}(\mathrm{n}, \mathrm{p})^{48} \mathrm{Sc}$ & -3.53 & -1.44 & 2.12 \\
\hline${ }^{54} \mathrm{Fe}(\mathrm{n}, \mathrm{p}){ }^{54} \mathrm{Mn}$ & 4.73 & 1.47 & -3.21 \\
\hline${ }^{56} \mathrm{Fe}(\mathrm{n}, \mathrm{p}){ }^{56} \mathrm{Mn}$ & 0.62 & 0.68 & 0.06 \\
\hline${ }^{93} \mathrm{Nb}(\mathrm{n}, 2 \mathrm{n})^{92 \mathrm{~m}} \mathrm{Nb}$ & -5.73 & -0.8 & 4.97 \\
\hline${ }^{115} \operatorname{In}\left(\mathrm{n}, \mathrm{n}^{\prime}\right)^{115 \mathrm{~m}} \operatorname{In}$ & -6.88 & -6.52 & 0.39 \\
\hline${ }^{55} \mathrm{Mn}(\mathrm{n}, 2 \mathrm{n}){ }^{54} \mathrm{Mn}$ & 4.41 & 5.43 & 0.97 \\
\hline${ }^{59} \mathrm{Co}(\mathrm{n}, 2 \mathrm{n}){ }^{58} \mathrm{Co}$ & 10.49 & 14.38 & 3.40 \\
\hline${ }^{60} \mathrm{Ni}(\mathrm{n}, \mathrm{p}){ }^{60} \mathrm{Co}$ & -4.88 & -0.88 & 4.04 \\
\hline${ }^{58} \mathrm{Fe}(\mathrm{n}, \gamma){ }^{59} \mathrm{Fe}$ & 33.08 & 0.54 & -32.37 \\
\hline${ }^{23} \mathrm{Na}(\mathrm{n}, \gamma)^{24} \mathrm{Na}$ & 30.52 & 0.28 & -30.16 \\
\hline${ }^{45} \mathrm{Sc}(\mathrm{n}, \gamma){ }^{46} \mathrm{Sc}$ & 13.71 & -0.28 & -14.03 \\
\hline${ }^{55} \mathrm{Mn}(\mathrm{n}, \gamma)^{56} \mathrm{Mn}$ & 17.16 & -0.59 & -17.86 \\
\hline${ }^{59} \mathrm{Co}(\mathrm{n}, \gamma){ }^{60} \mathrm{Co}$ & 38.47 & -0.11 & -38.62 \\
\hline${ }^{63} \mathrm{Cu}(\mathrm{n}, \gamma){ }^{64} \mathrm{Cu}$ & 2.38 & -2.15 & -4.63 \\
\hline${ }^{98} \mathrm{Mo}(\mathrm{n}, \gamma){ }^{99} \mathrm{Mo}$ & 15.61 & 0.06 & -15.54 \\
\hline${ }^{115} \operatorname{In}(\mathrm{n}, \gamma)^{116 \mathrm{~m}} \operatorname{In}$ & 18.21 & 0.8 & -17.27 \\
\hline${ }^{197} \mathrm{Au}(\mathrm{n}, \gamma){ }^{198} \mathrm{Au}$ & -0.92 & -0.46 & 0.46 \\
\hline${ }^{58} \mathrm{Fe}(\mathrm{n}, \gamma){ }^{59} \mathrm{Fe}-\mathrm{BB}$ & 36.33 & 4.61 & -30.32 \\
\hline${ }^{59} \mathrm{Co}(\mathrm{n}, \gamma){ }^{60} \mathrm{Co}-\mathrm{BB}$ & 18.25 & 0.69 & -17.44 \\
\hline${ }^{98} \mathrm{Mo}(\mathrm{n}, \gamma){ }^{99} \mathrm{Mo}-\mathrm{BB}$ & 25.75 & 2.48 & -22.71 \\
\hline${ }^{197} \mathrm{Au}(\mathrm{n}, \gamma){ }^{198} \mathrm{Au}-\mathrm{BB}$ & 2.33 & -6.11 & -8.99 \\
\hline${ }^{235} \mathrm{U}(\mathrm{n}, \mathrm{f}) \mathrm{FP}-\mathrm{BB}$ & 6.86 & 0.76 & -6.05 \\
\hline${ }^{238} \mathrm{U}(\mathrm{n}, \mathrm{f}) \mathrm{FP}-\mathrm{BB}$ & 1.3 & 0.56 & -0.74 \\
\hline${ }^{237} \mathrm{~Np}(\mathrm{n}, \mathrm{f}) \mathrm{FP}-\mathrm{BB}$ & -3.86 & -0.53 & 3.35 \\
\hline${ }^{239} \mathrm{Pu}(\mathrm{n}, \mathrm{f}) \mathrm{FP}-\mathrm{BB}$ & 2.78 & -1.85 & -4.72 \\
\hline
\end{tabular}

Note: BB indicates Boron Ball irradiation, $\mathrm{Cd}$ indicates cadmium covered irradiation.
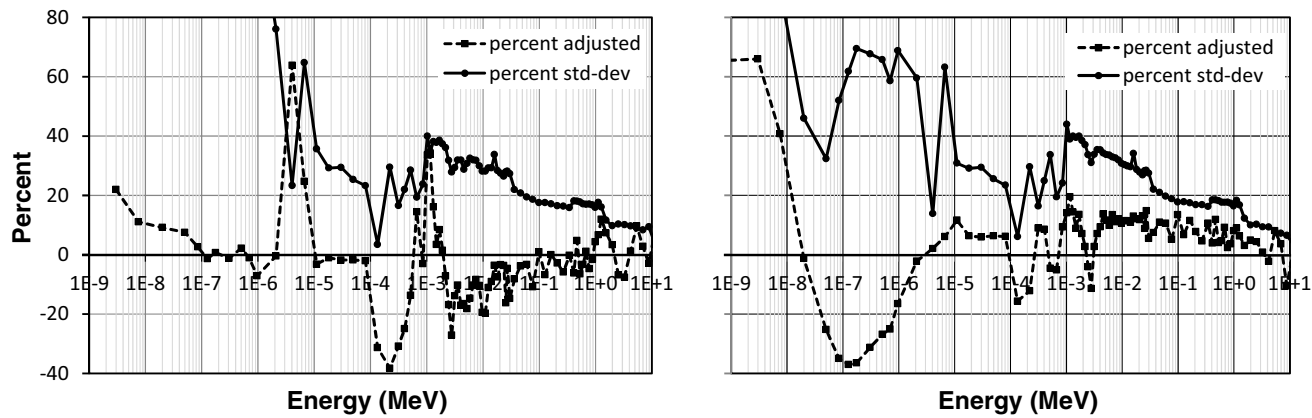

Figure 6. LSL adjustment percentages to the trial spectrum and the adjusted uncertainties as a function of energy for the LB44 bucket (left) and the PLG bucket (right). 


\section{$15^{\text {th }}$ ISRD}

Table 2. C/E values for the trial and adjusted LSL neutron energy spectrum for the PLG bucket.

\begin{tabular}{|c|c|c|c|}
\hline Activation Reaction & $\begin{array}{c}\mathrm{C} / \mathrm{E}-1 \\
\text { Trial Spectrum }(\%)\end{array}$ & $\begin{array}{c}\mathrm{C} / \mathrm{E}-1 \\
\text { Adjusted Spectrum (\%) }\end{array}$ & Factor Adjusted (\%) \\
\hline${ }^{58} \mathrm{Ni}(\mathrm{n}, \mathrm{p}){ }^{58} \mathrm{Co}-$ Reference & 0.00 & -0.59 & -0.59 \\
\hline${ }^{24} \mathrm{Mg}(\mathrm{n}, \mathrm{p})^{24} \mathrm{Na}$ & 9.80 & 3.63 & -5.95 \\
\hline$\left.{ }^{27} \mathrm{Al}(\mathrm{n}, \alpha)\right)^{24} \mathrm{Na}$ & 4.53 & -1.78 & -6.42 \\
\hline${ }^{32} \mathrm{~S}(\mathrm{n}, \mathrm{p}){ }^{32} \mathrm{P} \mathrm{Cf}-\mathrm{equ}$ & 7.83 & 4.36 & -3.33 \\
\hline${ }^{46} \mathrm{Ti}(\mathrm{n}, \mathrm{p})^{46} \mathrm{Sc}$ & 5.03 & 2.72 & -2.25 \\
\hline${ }^{47} \mathrm{Ti}(\mathrm{n}, \mathrm{p})^{47} \mathrm{Sc}$ & -2.57 & -2.48 & 0.09 \\
\hline${ }^{48} \mathrm{Ti}(\mathrm{n}, \mathrm{p})^{48} \mathrm{Sc}$ & 4.71 & 0.01 & -4.70 \\
\hline${ }^{55} \mathrm{Mn}(\mathrm{n}, 2 \mathrm{n}){ }^{54} \mathrm{Mn}$ & -21.33 & -16.85 & 5.39 \\
\hline${ }^{54} \mathrm{Fe}(\mathrm{n}, \mathrm{p}){ }^{54} \mathrm{Mn}$ & 1.37 & 0.56 & -0.81 \\
\hline${ }^{56} \mathrm{Fe}(\mathrm{n}, \mathrm{p}){ }^{56} \mathrm{Mn}$ & 0.90 & -1.36 & -2.29 \\
\hline${ }^{59} \mathrm{Co}(\mathrm{n}, \mathrm{p}){ }^{59} \mathrm{Fe}$ & 1.26 & -0.01 & -1.27 \\
\hline${ }^{59} \mathrm{Co}(\mathrm{n}, 2 \mathrm{n}){ }^{58} \mathrm{Co}$ & -4.01 & 0.39 & 4.38 \\
\hline${ }^{58} \mathrm{Ni}(\mathrm{n}, 2 \mathrm{n})^{57} \mathrm{Ni}$ & -2.05 & 5.48 & 7.14 \\
\hline${ }^{60} \mathrm{Ni}(\mathrm{n}, \mathrm{p}){ }^{60} \mathrm{Co}$ & -1.07 & -2.64 & -1.61 \\
\hline${ }^{63} \mathrm{Cu}(\mathrm{n}, \alpha){ }^{60} \mathrm{Co}$ & -16.12 & -17.5 & -1.67 \\
\hline${ }^{64} \mathrm{Zn}(\mathrm{n}, \mathrm{p}){ }^{64} \mathrm{Cu}$ & -1.52 & -2.52 & -1.03 \\
\hline${ }^{90} \mathrm{Zr}(\mathrm{n}, 2 \mathrm{n}){ }^{89} \mathrm{Zr}$ & -9.17 & -1.87 & 7.44 \\
\hline${ }^{93} \mathrm{Nb}(\mathrm{n}, 2 \mathrm{n})^{92 \mathrm{~m}} \mathrm{Nb}$ & 2.16 & 0.4 & -1.75 \\
\hline${ }^{115} \operatorname{In}\left(\mathrm{n}, \mathrm{n}^{\prime}\right)^{115 \mathrm{~m}} \mathrm{In}$ & -7.89 & -7.11 & 0.84 \\
\hline${ }^{23} \mathrm{Na}(\mathrm{n}, \gamma){ }^{24} \mathrm{Na}$ & 24.56 & 1.34 & -22.91 \\
\hline${ }^{45} \mathrm{Sc}(\mathrm{n}, \gamma){ }^{46} \mathrm{Sc}$ & 21.72 & 0.08 & -21.62 \\
\hline${ }^{58} \mathrm{Fe}(\mathrm{n}, \gamma){ }^{59} \mathrm{Fe}$ & 20.61 & 0.07 & -20.53 \\
\hline${ }^{59} \mathrm{Co}(\mathrm{n}, \gamma){ }^{60} \mathrm{Co}$ & 20.58 & -0.55 & -21.25 \\
\hline${ }^{63} \mathrm{Cu}(\mathrm{n}, \gamma){ }^{64} \mathrm{Cu}$ & 16.50 & -2.45 & -19.43 \\
\hline${ }^{98} \mathrm{Mo}(\mathrm{n}, \gamma){ }^{99} \mathrm{Mo}$ & 0.97 & 0.4 & -0.57 \\
\hline${ }^{197} \mathrm{Au}(\mathrm{n}, \gamma){ }^{198} \mathrm{Au}$ & 7.78 & -0.34 & -8.15 \\
\hline${ }^{23} \mathrm{Na}(\mathrm{n}, \gamma){ }^{24} \mathrm{Na}-\mathrm{Cd}$ & 11.43 & 0.53 & -10.84 \\
\hline${ }^{45} \mathrm{Sc}(\mathrm{n}, \gamma){ }^{46} \mathrm{Sc}-\mathrm{Cd}$ & 5.51 & -0.64 & -6.19 \\
\hline${ }^{55} \mathrm{Mn}(\mathrm{n}, \gamma){ }^{56} \mathrm{Mn}-\mathrm{Cd}$ & 2.28 & -0.68 & -2.98 \\
\hline${ }^{58} \mathrm{Fe}(\mathrm{n}, \gamma){ }^{59} \mathrm{Fe}-\mathrm{Cd}$ & 7.30 & 0.72 & -6.53 \\
\hline${ }^{59} \mathrm{Co}(\mathrm{n}, \gamma)^{60} \mathrm{Co}-\mathrm{Cd}$ & 16.79 & 0.13 & -16.64 \\
\hline${ }^{63} \mathrm{Cu}(\mathrm{n}, \gamma)^{64} \mathrm{Cu}-\mathrm{Cd}$ & 9.54 & 1.46 & -7.96 \\
\hline${ }^{98} \mathrm{Mo}(\mathrm{n}, \gamma)^{99} \mathrm{Mo}-\mathrm{Cd}$ & -2.43 & -0.45 & 1.99 \\
\hline${ }^{197} \mathrm{Au}(\mathrm{n}, \gamma){ }^{198} \mathrm{Au}-\mathrm{Cd}$ & 2.58 & 0.25 & -2.32 \\
\hline${ }^{235} \mathrm{U}(\mathrm{n}, \mathrm{f}) \mathrm{FP}-\mathrm{BB}$ & -7.27 & -4.88 & 2.51 \\
\hline${ }^{238} \mathrm{U}(\mathrm{n}, \mathrm{f}) \mathrm{FP}-\mathrm{BB}$ & 1.49 & 1.88 & 0.38 \\
\hline${ }^{239} \mathrm{Pu}(\mathrm{n}, \mathrm{f}) \mathrm{FP}-\mathrm{BB}$ & 5.97 & 4.72 & -1.19 \\
\hline
\end{tabular}

Note: BB indicates Boron Ball irradiation, $\mathrm{Cd}$ indicates cadmium covered irradiation.

Figure 5 shows that the $\mathrm{B}_{4} \mathrm{C}$ in LB44 is very effective in removing thermal and epithermal neutrons from the experiment region of the cavity. The polyethylene in the PLG bucket is equally effective in enhancing the thermal neutrons. The fine structure found in the 640-energy group trial spectrum is real and is due to cross-section resonances in the uranium fuel. The coarser 89-energy group trial spectrum smears out much of the fine detail in the spectrum.

For the LB44 bucket, the LSL analysis does not adjust the spectrum very much over the epithermal and fast energy range, as is visually observed in Fig. 5 and calculated in Fig. 6. The largest adjustment is found between the neutron energies of $10^{-4}$ and $10^{-2} \mathrm{MeV}(0.1-10 \mathrm{keV})$. The dosimetry response 

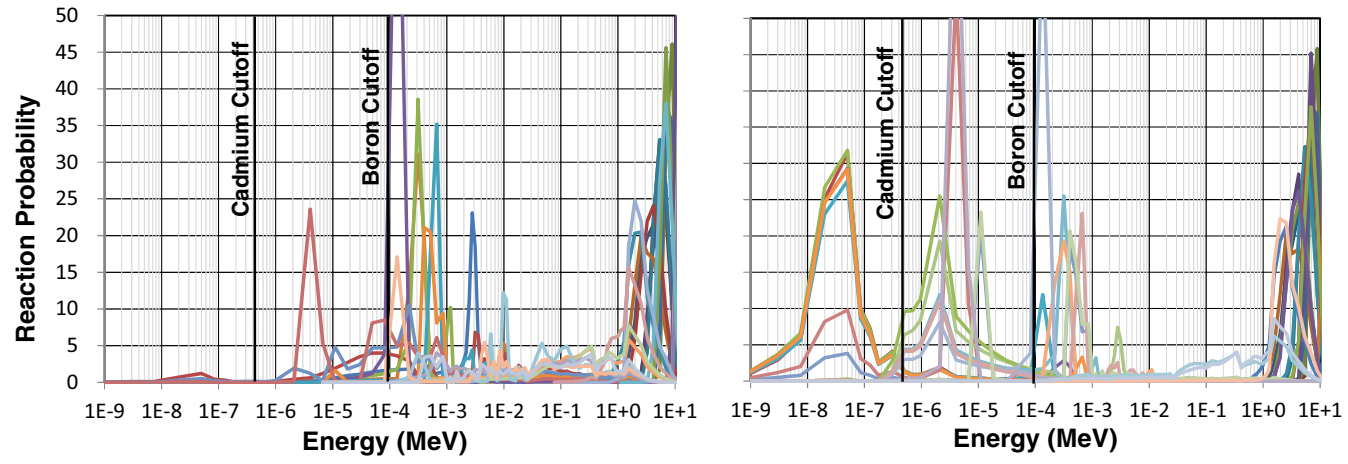

Figure 7. Dosimetry foil reaction probability as a function of energy for the LB44 bucket (left) and the PLG bucket (right). The area under each foil curve is equal to one. The reaction probabilities were generated in LSL using the adjusted spectrum.

(Fig. 7) shows good coverage over most of the relevant energy range, from $10^{-5}$ to $10^{1} \mathrm{MeV}(10 \mathrm{eV}-$ $10 \mathrm{MeV})$ with less coverage in the $10^{-2}$ to $10^{0} \mathrm{MeV}(10 \mathrm{keV}-1 \mathrm{MeV})$ range. These results indicate that the MCNP ACRR model and neutronic calculations of the LB44 bucket are of high fidelity and are consistent with the experimental results.

For the PLG bucket, the LSL analysis does not adjust the spectrum very much in the epithermal and fast energy range, as is visually observed in Fig. 5 and calculated in Fig. 6. More significant adjustment is found in the thermal region between $10^{-8}$ to $10^{-6} \mathrm{MeV}(0.01-1.0 \mathrm{eV})$. In the thermal region, the fluence is significantly lower than the calculated value. The dosimetry response (Fig. 7) shows good coverage over most of the relevant energy range, from $10^{-9}$ to $10^{1} \mathrm{MeV}(0.001 \mathrm{eV}-10 \mathrm{MeV})$ with less coverage in the $10^{-3}$ to $10^{0} \mathrm{MeV}(1 \mathrm{keV}-1 \mathrm{MeV})$ range. These results indicate that the MCNP ACRR model and neutronic calculations of the PLG bucket are adequate in that the neutron fluence results are within the uncertainty bounds. However, further investigation is required to determine if the PLG bucket model is of sufficient fidelity or if a different parameter in MCNP requires further study that would allow for better agreement in the thermal energy range of the spectrum. Modeling parameters to be reconsidered include the mass of the polyethylene and the graphite in the bucket. MCNP parameters include cross-section and $\mathrm{S}(\alpha, \beta)$ scattering kernel evaluations and temperatures.

\section{Conclusions}

A high-fidelity neutron spectrum characterization has been performed for the LB44 and PLG bucket environments in the ACRR central cavity. MCNP models were developed and trial spectra used with dosimetry-quality activation foils in order to determine a characterized neutron energy spectrum for each environment using the LSL-M2 code and the SNLRML and IRDFF dosimetry cross section libraries. The MCNP models, characterized neutron spectrum, and uncertainty and covariance matrix are available for use by experimenters. The prompt and delayed gamma-ray spectra and uncertainty and covariance matrices are also available. The ACRR facility, including the FREC-II and radiography unit and the RML counting laboratory, are all fully operational and available for use by experimenters. In addition, other central cavity and FREC-II cavity buckets are available for use. 


$$
15^{\text {th }} \text { ISRD }
$$

\section{References}

[1] MCNP-A General Monte Carlo N-Particle Transport Code, Version 5, Technical Report LA-UR03-1987 (2003)

[2] K. R. DePriest, P. J. Cooper, Edward J. Parma, "MCNP/MCNPX Model of the Annular Core Research Reactor," Technical Report SAND2006-3067 (2006)

[3] F. W. Stallmann, "LSL-M2: A Computer Program for Least-Squares Logarithmic Adjustment of Neutron Spectra,” Technical Report NUREG/CR-4349, ORNL/TM-9933 (1985)

[4] ASTM E720-11, "Standard Guide for Selection and Use of Neutron Sensors for Determining Neutron Spectra Employed in Radiation-Hardness Testing of Electronics," ASTM Int. (2011)

[5] P. J. Griffin, M. S. Luker, P. J. Cooper, D. W. Vehar, K. R. DePriest, C. V. Holm, "Characterization of ACRR Reference Benchmark Field," $11^{\text {th }}$ International Symposium on Reactor Dosimetry (2002)

[6] P. J. Griffin, "A Rigorous Treatment of Self-Shielding and Covers in Neutron Spectra Determination," IEEE Transactions on Nuclear Science, Vol 42, 6, pp. 1878-1885 (1995)

[7] P. J. Griffin, J. G. Kelly, T. F. Luera, "SNL RML Recommended Dosimetry Cross Section Compendium," Technical Report SAND92-0094 (1993)

[8] R. Capote, K. I. Zolotarev, V. G. Pronyaev, A. Trkov, "Updating and Extending the IRDF-2002 Dosimetry Library," JAI 9 (2012)

[9] E. M. Zsolnay, R. Capote, H. K. Nolthenius, A. Trkov, "Summary Description of the New International Reactor Dosimetry and Fusion File (IRDFF),” Technical Report INDC-0616 (2012) 